\title{
As críticas de Amartya Sen à teoria da escolha social de Kenneth Arrow
}

Amartya Sen's criticism of Kenneth Arrow's social choice theory

Bruno Beltrame

Pontifícia Universidade Católica de São Paulo

Laura Valladão de Mattos

Universidade de São Paulo

\section{Abstract}

This article attempts to systematize Amartya Sen's criticism of Arrow's theoretical structure and to show how, in order to avoid the devastating results of the impossibility theorem, Sen argues for the expansion of the universe of information used as the basis of social choice. Initially, this article gives a brief summary of Arrow's social choice theory with the purpose of providing a broad context to aid the understanding of the nature of Sen's criticisms. Next, it presents Sen's interpretations of the reasons that led to the impossibility result and this author's criticism of the foundations of Arrow's theory. Finally, some considerations are presented concerning the nature of Sen's criticism and its consequences for the views on welfare that he eventually adopted.

\section{Keywords}

Amartya Sen; social choice; Kenneth Arrow; impossibility theorem; informational basis.

JEL Codes B41; B29.

\section{Resumo}

Este artigo visa sistematizar as críticas que Amartya Sen dirige à estrutura teórica adotada por Arrow e mostrar como, para fugir dos resultados devastadores do teorema da impossibilidade, Sen defende a ampliação do universo de informações a serem utilizadas para embasar a escolha social. Inicialmente é apresentado um breve apanhado da teoria da escolha social de Arrow com o objetivo de fornecer o pano de fundo para a compreensão das críticas que Sen dirige a esse sistema teórico. Em seguida são expostas as interpretações de Sen sobre as razões que levaram ao resultado da impossibilidade e as críticas que este autor dirige aos fundamentos da teoria de Arrow. Por fim, são tecidas algumas considerações sobre a natureza desta reflexão crítica e suas consequências para a visão de bem-estar posteriormente adotada porSen.

\section{Palavras-chave}

Amartya Sen; escolha social; Kenneth Arrow; teorema da impossibilidade; base informacional.

Códigos JEL B41; B29. 


\section{Introdução}

A "abordagem das capacitações" de Amartya Sen representa um importante marco no campo da teoria do bem-estar social ao propor uma ampliação dos elementos a serem considerados na discussão de bem-estar e utilizados na avaliação de estados sociais alternativos - afastando-se do utilitarismo estreito que dominava as reflexões nessa esfera. Além de ter importantes implicações teóricas, essa ampliação do que ele denomina de "base informacional" resultou em uma nova perspectiva no campo de políticas públicas, especialmente no combate à pobreza, à fome e à desigualdade $^{1}$. Por essas razões, a abordagem das capacitações representou uma tentativa bem sucedida de reintrodução de um posicionamento ético mais demarcado na agenda de discussões da economia do bem-estar.

Sem dúvida, o "estrago" causado na economia do bem-estar e na teoria de escolha social pelo Teorema da Possibilidade Geral (ou Teorema da Impossibilidade) de Kenneth Arrow foi um ponto de inflexão no pensamento de Sen. Segundo o próprio autor, esse resultado surpreendente levou a um impasse e a um pessimismo generalizado no campo da escolha social (Sen, 2002, p. 69). Ao invés de abrir mão do projeto de chegar a uma função de escolha social a partir da consideração das escolhas individuais, a reação de Sen foi direcionar seus esforços no sentido de mostrar as fragilidades da estrutura arroviana e de apresentar alternativas para o "beco sem saída" ao qual essa estrutura levou. Em parte, como fruto dessas reflexões, ele elaborou a sua nova forma de abordar o problema da escolha social e de medir bem-estar social.

Este artigo visa sistematizar as críticas que Sen dirige à estrutura teórica adotada por Arrow e mostrar como, para fugir aos resultados devastadores do teorema da Impossibilidade, Sen defende a ampliação do universo de informações a serem utilizadas para embasar a escolha social. $O$ esforço empreendido neste artigo se justifica, pois, apesar da reconhecida importância de Arrow para o desenvolvimento da teoria de Sen, não conhecemos na literatura nenhum trabalho que reúna, sistematicamente, as críticas de Sen às premissas fundamentais do sistema teórico desenvolvido por Arrow (1963). ${ }^{2}$

1 Uma implicação prática importante foi a elaboração do Índice de Desenvolvimento Humano (IDH), que foi abertamente inspirado na abordagem das capacitações de Sen.

2 É relevante notar que muito mais explorada na literatura é a influência que Rawls exerceu 
Com esse objetivo em mente, o artigo é composto por três seções, além desta introdução. Inicialmente é apresentado um breve apanhado da teoria da escolha social de Arrow com o objetivo de fornecer o pano de fundo para a compreensão das críticas que Sen dirige a esse sistema teórico. Em seguida são expostas as interpretações de Sen sobre as razões que levaram ao resultado da impossibilidade e as críticas que dirige aos fundamentos da teoria de Arrow. Por fim, na última seção, são tecidas algumas considerações sobre a natureza desta reflexão crítica e suas consequências para a visão de bem-estar posteriormente adotada por Sen.

\section{A teoria da escolha social desenvolvida por Kenneth Arrow}

Para entendermos as contribuições de Kenneth Arrow e o teor das críticas que Sen dirige ao esquema apresentado por esse autor, é interessante descrever, ainda que de forma rápida, a guinada ocorrida no campo da economia do bem-estar social nas décadas de 1930/40, com o abandono da "velha" e o advento de uma "nova" escola.

\subsection{A "velha" e a "nova" escola do bem-estar social}

A chamada "velha" escola de bem-estar social, ou, "tradicional economia do bem-estar", que teve como seus principais expoentes Pigou, Ramsey, Marshall e outros (Sen, 2002, p. 7-8), tinha como base a visão benthamista e utilitarista de bem-estar, de que seria possível somar e subtrair as utilidades individuais de modo a avaliar os impactos da adoção de diferentes instituições ou políticas sobre a felicidade geral.

Essa visão de que seria possível contabilizar os ganhos e as perdas de utilidades dos diferentes indivíduos (dando pesos iguais para todos os indivíduos), associados a diferentes arranjos sociais, foi utilizada para defender determinadas políticas com base na ideia de que aumentariam a felicidade total da sociedade. Por exemplo, como aponta Hands, na virada do século $\mathrm{XX}$, era comum a afirmação de que "[...] por conta da utilidade marginal 
decrescente da renda monetária, uma transferência de renda de um rico para um pobre iria necessariamente aumentar o bem-estar social (a soma das utilidades individuais)." (Hands, 2001, p. 36).

Essa concepção da visão utilitarista de bem-estar foi atacada com veemência por Lionel Robbins, que, influenciado pelo positivismo lógico, defendeu a impossibilidade de comparações interpessoais de utilidade. Para ele:

Não há meios de testar a magnitude da satisfação de A quando comparada a de B. [...] A introspecção não permite a A medir o que está ocorrendo na mente de B, ou a B medir o que ocorre na de A. Não há meios de comparar as satisfações de diferentes pessoas. (Robbins, 1932, p. 124, grifo no original).

Assim, como ressalta Hands, "[...] essas comparações não envolvem coisas observáveis [observables] e, portanto, não são passíveis de investigações científicas." (Hands, 2001, p. 36). Como consequência, Robbins defendeu que a economia enquanto ciência deveria abandonar o procedimento de utilizar comparações interpessoais com base em medidas cardinais de utilidade, e colocar de lado as conclusões distributivas que derivavam destas no campo da teoria do bem-estar. ${ }^{3}$

Essa posição de Robbins revelou-se muito influente e os economistas de uma forma geral passaram a aceitar que comparações interpessoais de utilidade não eram científicas. Assim, como descreve Sen, "[...] o fundamento epistêmico da teoria do bem-estar utilitarista passou a ser visto como incuravelmente falho" (Sen, 2002, p. 71). Ainda segundo o autor, isso reduziu ainda mais a base informacional a partir da qual se tomava decisões no campo do bem-estar social. Se os utilitaristas já haviam excluído todas as informações não relacionadas à utilidade, excluía-se agora, adicionalmente, a possibilidade de se medir e de agregar utilidades (Sen, 2002, p. 265). Nesse contexto, o desafio passou a ser "[...] descobrir novos fundamentos para a economia do bem-estar com base em informações ordinais e não-interpessoalmente comparáveis de utilidade [...]" (Suzumura, 2002, p. 6, grifo no original).

A chamada Nova Economia do Bem-Estar abraçou esse desafio. Como aponta Sen (2002, p. 71), a partir de então, foi adotado como único critério

3 A respeito disso Robbins afirma: "Acredita-se às vezes que alguns desenvolvimentos na Teoria Econômica moderna fornecem, por si mesmos, um conjunto de normas capazes de prover uma base para a prática de políticas. A Lei da Utilidade Marginal decrescente é tida como fornecendo um critério para todas as formas de atividades políticas e sociais que afetam a distribuição [...] Eu me atrevo a sugerir que elas [as políticas] não encontram nenhuma justificativa em qualquer doutrina econômica científica [...]" (Robbins, 1932, p. 121). 
de avaliação de melhoramento social o critério de Pareto - ou seja, se pelo menos um indivíduo se encontra em uma situação melhor, sem que isso signifique a piora da situação de nenhum dos demais, é possível afirmar que a sociedade encontra-se em uma situação melhor. ${ }^{4}$ No entanto, como sugere o autor, com esse critério não era possível ir muito longe, pois nada se poderia dizer sobre questões distributivas nas quais ocorrem conflitos de interesses ou preferências - o que fazia, evidentemente, com que fosse um critério muito limitado para avaliações de bem-estar social. ${ }^{5}$

Suzumura afirma que duas abordagens teóricas alternativas passaram a ser exploradas na época com vistas a ir além do critério de Pareto. Uma envolvia a tentativa, feita por Kaldor, Hicks, Scitovsky e Samuelson, de trabalhar com critérios de compensação e "[...] buscava expandir a aplicabilidade do princípio de Pareto ao introduzir pagamentos compensatórios entre os beneficiados e os prejudicados por uma mudança na política econômica." (Suzumura, 2002, p. 7). A outra, encampada por Bergson em 1938 e exposta/desenvolvida por Samuelson nos seus Foundations, publicado inicialmente em 1947, envolvia a criação de uma função de bem-estar Social - que viria a ser conhecida como a função de bem-estar social de Bergson-Samuelson. E essa foi a linha seguida, posteriormente, por Arrow. ${ }^{6}$

Essa função de bem-estar social prescindia das comparações interpessoais de utilidade típicas das análises da velha economia do bem-estar toda a análise sendo desenvolvida em termos ordinais - e, escapava, dessa forma, às principais críticas de Robbins. A ideia era chegar a uma função de bem-estar social a partir das decisões individuais, no entanto, apesar de se manter o conceito de utilidade como principal argumento dessa função,

4 O que foi descrito acima é o que se denomina Paretianismo forte. Em seu livro, Samuelson adota o que se denomina Paretianismo fraco, que diz que uma posição ótima no sentido de Pareto seria "[...] definida pela exigência de que não existe nenhuma variação ou movimento possível que colocaria a todos em uma situação melhor" (Samuelson, 1963, p. 212).

5 Samuelson viu com clareza essa limitação, como fica claro na seguinte passagem do Foundations: "Dentro do sistema de Pareto é impossível decidir [...] qual de dois pontos sobre o que pode ser chamado de 'locus de contrato generalizado' [ou curva de contrato] é melhor; ou mesmo que um dado movimento para fora do locus de contrato e, portanto, para um ponto sub-ótimo, é bom ou ruim. [...]" (Samuelson, 1963, p. 214).

6 Descrevendo a situação da economia do bem-estar quando ele começou a estudar a área, Sen expõe em grandes linhas a existência dessas mesmas posturas: Sobre a vertente Bergson-Samuelson, que culmina em Arrow, Sen afirma que buscou "[...] funções de bem-estar social que podemos utilizar sem muita base informacional, em particular sem utilizar comparações interpessoais de utilidade ou fazer uso de informações não concernentes à utilidade [...]" (Sen apud Klamer, 1989, p. 140). E comenta: "[...] o teorema de impossibilidade de Arrow revela a pobreza informacional de tal aparato" (Sen apud Klamer, 1989, p. 140). 
utilidade passou a estar associada apenas a escolhas individuais e não mais a intensidades cardinais relativas a estados mentais individuais.

Segundo Suzumura, essa linha seguida por Bergson e Samuelson foi mais bem sucedida do que aquela dos critérios de compensação e "[...] é louvada como ápice da abordagem 'científica' ordinalista à Economia do Bem-Estar Social." (Suzumura, 2002, p.8).

Segundo Sen, a Nova Economia do Bem-Estar passou a aceitar como legítimas para a definição da função de bem-estar social as seguintes características normativas: 1) Welfarismo - que indica que a função de bem-estar social tem que ser função das utilidades individuais e que as características dos estados sociais que não se refiram à utilidade devem ser ignoradas; 2) Ordinalismo; 3) Impossibilidade de comparação interpessoal de utilidade; 4) A regra de Pareto (Sen, 1982, p. 328).

Foi tendo esse contexto intelectual como pano de fundo que Kenneth Arrow desenvolveu a sua obra Social Choice \& Individual Values (1963) - que ao mesmo tempo ampliou o escopo dos assuntos tratados pela Economia do Bem-Estar e forneceu as bases para uma nova teoria da escolha social.

\subsection{Arrow e a teoria da escolha social}

Toda essa discussão empreendida pela Nova Economia do Bem-Estar Social - em especial por Bergson-Samuelson - exerceu grande influência sobre Arrow. No entanto, ele modificou em tal medida as questões tratadas por essa vertente que muitos consideram que as suas contribuições não se situam no campo da economia do bem-estar, mas no da escolha social. ${ }^{7}$ De toda forma, esses campos adotam uma perspectiva parecida. Como aponta Sen:

[...] os problemas da escolha social têm em comum a característica de relacionar a avaliação social - ou de grupo - aos valores, preferências, escolhas, ou a alguma outra característica dos respectivos indivíduos que formam a coletividade dessa sociedade ou grupo. (Sen, 2011, p. 30).

7 O próprio Samuelson é dessa opinião, conforme assinalou em entrevista dada a Suzumura: "Desde o começo eu achei inapropriado que Arrow tivesse utilizado a terminologia da Economia do Bem-Estar quando ele estava, na realidade, apresentando uma contribuição muito importante [path breaking] à disciplina da Política Matemática [mathematical politics]" (Samuelson apud Suzumura, 2004, p. 12). Afirma, ainda, que sua teoria "[...] não tinha nada a ver com ética e com economia do bem-estar. O uso por parte de Arrow da 'função de bem-estar social' para [denominar] a sua 'função de votação' foi infeliz." (Samuelson apud Suzumura, 2004, p. 12). 
À semelhança de Bergson e Samuelson, Arrow (1963) tem a percepção de que as funções de bem-estar social são um bom método de transformar decisões individuais em decisões coletivas. Além disso, ele aceita a ideia de que a melhor forma de se acessar as preferências seria por meio da observação das escolhas individuais - que, por essa razão, são assumidas como variáveis desta função. Ademais, como aponta Sen, aceitava as principais condições utilizadas pelos teóricos da Nova Economia do Bem-Estar como, por exemplo, o welfarismo, ordinalismo, impossibilidade de comparações interpessoais de utilidade e o paretianismo - apesar de em uma versão mais fraca (Sen, 1982, p. 328).

Uma diferença importante, no entanto, seria que enquanto Bergson-Samuelson localizam a fonte do valor social nas escolhas individuais, Arrow localiza a origem do valor social nas próprias escolhas sociais (Arrow, 1963, p. 106)..$^{8}$ Ou seja, enquanto para Bergson-Samuelson, o valor social significa tão somente o respeito aos valores individuais, sem a preocupação explícita com relação às características do processo de agregação das preferências individuais; em Arrow, valor social corresponde às regras ou procedimentos de escolha social. Essas devem, no seu entender, entre outras coisas, garantir a vinculação democrática entre a escolha social e os valores individuais. Como explica Suzumura:

Em contraste com a função de bem-estar social de Bergson-Samuelson, que Bergson e Samuelson assumiam ser dada externamente à Economia, Arrow tinha a convicção de que o processo ou regra pela qual o valor social, a ser representado pela função de bem-estar social de Bergson-Samuelson, é formado, também deveria ser assunto de escrutínio lógico. Em outras palavras, para que a análise econômica não perca relevância social, é necessário que o processo ou regra de construção da função de bem-estar social de Bergson-Samuelson com base nos julgamentos individuais sobre a adequação [goodness] dos estados sociais [...] tenha que satisfazer o requerimento mínimo de legitimidade democrática e eficiência informacional[...]. (Suzumura, 2002, p. 11).

É por essa razão que na segunda edição de Social Choice \& Individual Values, publicada em 1963, Arrow sugere que talvez tivesse sido melhor nomear o seu processo de determinação de um ordenamento social de "constituição" e não de função de bem-estar social (Arrow, 1963, p. 104-5). E, de fato, o termo "constituição" parece ser mais apropriado, uma vez que as pre-

8 Como para Arrow a questão da escolha social era prioritária, ele criou no seu sistema teórico um conjunto de regras que, em princípio, visava garantir que não ocorressem situações nas quais a decisão social não fosse possível. Na verdade, como veremos, ele chega ao resultado da impossibilidade desse objetivo. 
missas do teorema de Arrow são, na verdade, um conjunto de exigências às quais a função de bem-estar social deve se submeter. É nesse sentido que podemos entender a afirmação de Samuelson de que "Arrow queria descobrir como uma função individualista de bem-estar social de Bergson-Samuelson poderia ser gerada de forma democrática." (Samuelson, apud Suzumura, 2004, p. 15). E foi justamente a introdução dessas exigências na função de bem-estar (ou "constituição") de Arrow - que não representavam uma preocupação para Bergson e Samuelson - que engendrou, como será visto, o resultado da impossibilidade. ${ }^{9}$

\subsection{Arrow e o teorema da impossibilidade}

Como aponta Sen, desde os seus primórdios, a teoria da escolha social (com Borda e Condorcet) esteve comprometida com os princípios democráticos de que "[...] os julgamentos sociais e decisões públicas têm que depender de uma forma transparente das preferências individuais, entendidas de forma ampla.", e de que "[...] pelo menos em princípio as preferências de todos deveriam contar [...]" (Sen, 2011, p. 32). E Arrow, como vimos, não foi uma exceção nessa tradição.

$\mathrm{Na}$ busca por uma função de bem-estar social que representasse a sua noção de valor social, Arrow (1963) estabeleceu quatro condições que garantiriam que a função satisfizesse, ao mesmo tempo, critérios de eficiência e de democracia. As quatro condições podem ser descritas da seguinte forma: ${ }^{10}$

Condição 1: Princípio de Pareto. "Se $x P_{i} y$ para todo $i$, então $x P y$. [...] Em palavras, "[...] se cada indivíduo prefere $x$ a $y$, então assim também é para a sociedade" (Arrow, 1963, p. 96).

9 Em entrevista a Suzumura, Samuelson afirma que "[o] teorema da impossibilidade de Arrow não invalida [disprove] a existência de uma função de bem-estar social Bergsoniana, tampouco invalida a existência de uma função hedonista Benthamiana." (Samuelson apud Suzumura, 2004, p. 13). De fato, o resultado de Impossibilidade decorre de exigências que Arrow impõe à escolha social, que são alheias à preocupação de Bergson e Samuelson. O próprio Suzumura, em uma nota explicativa à entrevista, concorda: "[...] agora já há um reconhecimento geral de que o teorema da impossibilidade geral de Arrow [...] é um teorema sobre a não-existência da função de bem-estar social, ou constituição, de Arrow, e não sobre a não-existência da função de bem-estar social de Bergson." (Suzumura, 2004, p. 13).

10 Deve-se considerar para as próximas páginas as seguintes notações: $R=$ relação fraca de preferência; $P=$ relação forte de preferência; $x P_{i} y=$ "indivíduo $i$ prefere $x$ a $y$ "; $x P y=$ " $x$ é socialmente preferido a $y^{\prime \prime}$. 
Ou seja, a preferência social deve responder positivamente à situação de unanimidade.

Para se entender a segunda condição, é necessário uma explicação adicional sobre o termo ordenamento, que para Arrow significa uma relação entre elementos que respeita certos pressupostos de racionalidade. Em Social Choice \& Individual Values (1963, p. 13), o autor expõe dois axiomas elementares de racionalidade:

Axioma I: para todo $x$ e $y$, ou $x R y$ ou $y R x$; caracterizando a completude e,

Axioma II: para todo $x, y$, e $z, x R y$ e $y R z$ implica $x R z$; caracterizando a transitividade.

A partir destes dois axiomas, Arrow (1963, p. 13) define que "uma relação que satisfaça os Axiomas I e II é dita ordenamento fraco ou às vezes simplesmente ordenamento". A partir dessa observação, é possível entender a condição seguinte.

Condição 2: Todos os ordenamentos logicamente possíveis dos estados sociais alternativos são admissíveis (Arrow, 1963, p. 96).

Em outras palavras, a função de bem-estar social deve sempre ser capaz de agregar as preferências individuais em um ordenamento social, que para Arrow representa uma relação de preferência completa e transitiva. ${ }^{11} \mathrm{Ou}$ seja, função de bem-estar social sempre deve ser capaz de representar racionalmente as preferências individuais pelos estados sociais.

Condição 3: Independência de Alternativas Irrelevantes. Seja $R_{1}, \ldots, R_{n}$ e $R_{1}{ }^{\prime}, \ldots$ $\ldots, R_{n}{ }^{\prime}$ dois conjuntos de relações de ordenamentos individuais e sejam $C(S)$ e $C^{\prime}(S)$ as funções de escolha social correspondentes. Se, para todos os indivíduos $i$ e todo $x$ e $y$ em um dado ambiente $S, x R_{i} y$ se e apenas se $x R_{i}^{\prime} y$, então $C(S)$ e $C^{\prime}(S)$ são o mesmo (Arrow, 1963, p. 27).

Esta condição exige que a escolha social entre dois estados alternativos não dependa de nada além das escolhas entre essas duas alternativas feitas individualmente; ou ainda, nas palavras de Sen, "[...] requer que o ranking social de quaisquer dois estados $x$ e y dependa apenas dos rankings individuais destes dois estados" (Sen, 2002, p. 329). Assim, a escolha social entre dois estados deve refletir somente as preferências individuais por aqueles dois estados.

11 Strasnick (1976, p. 244) adota uma variante desta condição em que os dois axiomas de racionalidade são mais evidentes. Em seu texto, denomina-a de Condição de Racionalidade Coletiva, e é dada por: "para qualquer conjunto de ordenamentos de preferências individuais, o procedimento de escolha social determina um ordenamento completo e transitivo das opções [disponíveis] no ambiente". 
Condição 4: Não-Ditadura. "[...] a função de bem-estar social não deve ser ditatorial" (Arrow, 1963, p. 30).

Não existe "[...] uma tal pessoa que sempre que preferir qualquer $x$ a qualquer $y$, o resultado seja de que $x$ é socialmente preferido a $y$ " (Sen, 2002 , p. 329). Ou seja, nenhum indivíduo deve ser capaz de impor a sua vontade aos demais.

O problema é que Arrow chega ao resultado da Impossibilidade (1963, p. 97-100), ou seja, constata a impossibilidade lógica da existência de uma função de bem-estar social que atendesse ao mesmo tempo a essas quatro condições. ${ }^{12}$

Como as exigências da "constituição" de Arrow representavam uma maneira de requerer que a função de bem-estar social desenvolvida pela tradição precedente se comprometesse minimamente com a democracia no processo de escolha social, o resultado da impossibilidade mostrava que mesmo esse comprometimento mínimo seria impossível. ${ }^{13}$

Essa conclusão foi, segundo a descrição de Sen (2002, p. 326), "devastadora", já que aparentemente frustraria a possibilidade da construção de sistemas democráticos de decisão social que tomassem por base as preferências individuais.

De fato, seguiu-se, como mencionado anteriormente, um clima de pessimismo entre os teóricos do bem-estar e da escolha social. ${ }^{14}$ Mas talvez por Sen apresentar como traço de personalidade, segundo Atkinson, a atitude de "[...] sempre busca[r] fazer progresso construtivo - ver o que os economistas "podem fazer"' (Atkinson, 1999, p. 174), ao invés de sucumbir

12 Mais rigorosamente: a conclusão a que Arrow chega é a de que se o conjunto dos estados sociais for maior ou igual a três e se o número de participantes for finito, não existe uma função de bem-estar social que satisfaça as quatro condições simultaneamente (Sen, 2002, p. 329).

13 Este comprometimento é de fato mínimo, pois, apesar de garantir que o procedimento de escolha social seja democrático, ele nem mesmo exclui a possibilidade de que o resultado da escolha social seja uma ditadura. Para Sen, a garantia de um regime político democrático é fundamental.

14 Sen relata: "Em meados da década de 1960 William Baumol de forma pertinente afirmou que 'as afirmações sobre a importância da Economia do Bem-Estar' começaram a ter uma 'semelhança pouco disfarçada com obituários'. Essa era certamente uma leitura correta das visões prevalecentes." (Sen, 2002, p. 70). Ele afirma ainda que "Para evitar esse resultado da impossibilidade formas diferentes de modificar as exigências de Arrow foram tentadas na literatura que seguiu, mas outras dificuldades continuaram a surgir. A força e a presença abrangente dos resultados de impossibilidade geraram um sentido de pessimismo consolidado, e esse passou a ser o tema dominante da economia do Bem-Estar e da Escolha Social em geral." (Sen, 2002, p. 72-73). 
a esse pessimismo, ele partiu para repensar as bases da teoria da escolha social. O seu intuito era não só o de compreender melhor porque se chegou a esse resultado partindo de axiomas presumivelmente razoáveis, mas também de oferecer uma estrutura alternativa que evitasse esse beco sem saída ao qual o esquema teórico de Arrow levou os economistas.

$\bigcirc$ próprio Sen enfatiza esse lado construtivo do resultado da Impossibilidade: "Enquanto que o Teorema da Impossibilidade de Arrow é um resultado negativo, o desafio que ele colocou levou, de forma dialética, a um número grande de desenvolvimentos construtivos" (Sen, 2002, p. 274-5). Certamente entre esses desenvolvimentos está a sua teoria das capacitações.

Para entendermos a saída de Sen, e para chegarmos a uma compreensão adequada das profundas diferenças que existem entre as visões deste autor e de Arrow, faz-se necessária uma exposição mais detida das críticas mais importantes lançadas por Sen à construção arrovinana. Para tanto, iremos analisar a posição de Sen em relação a cada um dos 4 axiomas que compõem a "constituição" de Arrow - que, quando adotados conjuntamente, levaram ao resultado da Impossibilidade.

\section{As interpretações de Sen sobre o teorema da impossibilidade de Arrow}

Arrow entendia o resultado da Impossibilidade como uma decorrência natural da estrutura lógica de sua teoria, uma vez que ela "[...] corresponderia à generalização do paradoxo do votante" ${ }^{15}$ Nessa interpretação, a Impossibilidade decorreria da exigência de transitividade imposta pela Condição 2 (Sen, 2002, p. 330-32). Uma série de trabalhos, inclusive do próprio Sen (1982, p. 118-134), procurou apresentar saídas possíveis para o resultado da Impossibilidade de Arrow, relaxando algumas hipóteses, preservando, no entanto, o arcabouço teórico utilizado originalmente pelo autor.

Posteriormente, no entanto, Sen (1982) passa a considerar que os principais problemas da teoria da escolha social de Arrow não decorreriam

15 Esse paradoxo se refere à possibilidade de intransitividade quando se toma o voto majoritário como processo de escolha social. Sen, no entanto, acha que a adoção desse procedimento é inadequada também por outras razões. No caso, por exemplo, das decisões distributivas envolvendo indivíduos egoístas: "[...] a regra majoritária seria um procedimento de decisão terrível [...], e sua intransitividade dificilmente é o maior dos problemas." (Sen, 2002, p. 276). 
da exigência de transitividade, mas da estrutura analítica representada nas Condições 1 e 2 e da adoção da base informacional proposta pela Condição 3 .

Eu gostaria de argumentar que a Impossibilidade [de Arrow] pode ser vista como resultante da combinação de uma versão de welfarismo que exclui o uso de informações não referentes à utilidade, com tornar a informação sobre utilidade marcadamente pobre (particularmente ao excluir as comparações interpessoais). (Sen, 1982, p. 330). ${ }^{16}$

Ele revela também a convicção de que o abandono da pobreza informacional representaria uma saída frutífera ao problema colocado por Arrow:

Não só o teorema da Impossibilidade de Arrow é um resultado notável, de beleza analitica enorme, mas é também surpreendentemente robusto, dadas as restrições informacionais [...]. Por outro lado, rotas de escape genuinas emergem com resultados de possibilidades reais uma vez que as restrições informacionais são abandonadas ou enfraquecidas. (Sen, 1982, p. 337).

Como será visto, as reflexões de Sen levaram-no à conclusão de que para se chegar a uma estrutura adequada para analisar o bem-estar, e para se evitar definitivamente o problema da Impossibilidade, alguns posicionamentos éticos, que foram paulatinamente expurgados do campo da Economia, deveriam ser reincorporados. Seria, assim, na sua interpretação, necessário modificar de forma bastante profunda a estrutura de Arrow - com especial ênfase na expansão da base informacional utilizada, não só com a reintrodução ao campo da economia do bem-estar social da possibilidade de comparações interpessoais de utilidade, mas também com a introdução de informações não concernentes à utilidade que, como vimos, tradicionalmente ficaram de fora desse campo graças à sua origem utilitarista. ${ }^{17}$

Antes de analisarmos de forma mais detida as críticas que Sen direciona à estrutura de Arrow, é interessante notar que elas têm como alvo somente as três primeiras condições. ${ }^{18}$ A Condição 4 (de não-ditadura), como

16 Sen (2002) sugere que o grande problema estaria não na transitividade, mas no que ele denomina neutralidade implícita nos pressupostos de Arrow. A neutralidade significa que a escolha social não pode envolver nenhum viés, ou seja, ela deve ser feita apenas com base nas preferências individuais sobre os estados de coisas, sem qualquer consideração sobre outras características desses estados ou desses indivíduos. Nesse contexto, a existência de desigualdade de renda, por exemplo, não deve afetar a escolha sobre os estados.

$17 \bigcirc$ autor aborda a questão da pobreza informacional do sistema de Arrow e da necessidade de se ampliar a base informacional da teoria da escolha social em inúmeros textos, podemos citar, por exemplo, Sen (1982), Sen (2002) e Sen (2011).

18 É importante observar que algumas destas críticas desenvolvidas por Sen, e que serão adiante associadas às condições de Arrow, foram originalmente direcionadas a aspectos mais gerais do Utilitarismo econômico, mas que podem ser interpretadas como estando refletidas 
vimos, teria a função de garantir a priori que o processo de escolha social respeite o valor da democracia, e este era um ideal plenamente compartilhado pelo autor.

As demais condições já não têm o mesmo caráter. $O$ respeito à regra de Pareto (Condição 1) ou a exigência de racionalidade na escolha social (Condição 2) não envolvem um comprometimento forte com valores éticos. A Condição $3,-$ que requer que a "[...] escolha social de qualquer conjunto de alternativas dependa somente das preferências no que concerne a essas alternativas" (Sen, 2002, p. 72) - é criticada, por sua vez, justamente pela exclusão que promove da possibilidade de comparações interpessoais, ou seja, por excluir a adoção de um posicionamento ético mais específico (e que Sen julgava necessário assumir), por exemplo, de rejeição à pobreza, à desigualdade e à discriminação, ou a favor da liberdade e dos direitos humanos (Sen, 1982).

\subsection{Críticas associadas ao princípio de Pareto (Condição 1)}

Em seu artigo "The Impossibility of a Paretian Liberal" (1970), Sen apresenta uma crítica à adesão, geralmente considerada não problemática e incontroversa pelos economistas, ao princípio de Pareto - e que está representada na condição 1 de Arrow.

A questão que Sen se coloca é se esse princípio é compatível com um requisito mínimo de liberdade individual - e, de forma surpreendente, ele conclui que não é. ${ }^{19}$

Ele introduz, assim, uma nova impossibilidade, agora referente ao conflito entre a regra de Pareto e a garantia mínima do direito das pessoas "[...] decidirem certas coisas sobre suas próprias vidas" (Sen; Williams, 1982, p. 7). A conclusão é que, se for adotado como regra o princípio de Pareto, não é possível garantir que as pessoas possam sempre decidir individualmente, por exemplo, com qual cor pintarão suas paredes quando maioria das outras pessoas preferem paredes brancas, ou se dormirão de bruços, num

nas premissas ou nas próprias Condições de Arrow.

19 Como afirma Allen (1988): "O princípio de Pareto tem sido considerado com frequência o elemento mais inequívoco da economia do bem-estar. De acordo com esse critério, as preferências unânimes de todos os cidadãos têm que prevalecer na escolha social final. Mas o paradoxo de Sen indica que esse tipo de conflito [entre liberdade e o princípio de Pareto] pode ocorrer em algumas circunstâncias." (Allen, 1988, p. 57). 
contexto em que os outros consideram que o correto seja dormir de costas (Sen, 1970, p. 152). ${ }^{20}$

Para tornar esse resultado mais intuitivo, o autor utiliza no artigo um exemplo no qual a escolha social envolve a leitura do livro $O$ Amante de Lady Chaterley em uma situação na qual existem duas pessoas com gostos morais muito diferentes (um moralista e um libidinoso) e três estados sociais entre os quais se dá a escolha social: $p$ (o moralista lê o livro), l (o libidinoso lê o livro) e o (ninguém lê o livro). $O$ moralista prefere que ninguém leia o livro (que ele detesta por considerar imoral), mas se isso não for possível, ele prefere ler o livro a permitir que o libidinoso se divirta/ perverta com essa leitura. A ordenação do moralista dos estados sociais seria $(o, p, l)$. O libidinoso, por sua vez, prefere que o moralista leia o livro do que ler o livro, pois é de seu agrado ver o moralista em contato com algo que ele considera perverso, mas prefere ler o livro à situação na qual ninguém lê o livro - assim, a sua ordenação seria $(p, l, o)$. Como os dois indivíduos têm mais prazer na situação em que o moralista lê o livro do que naquela em que o libidinoso o lê, adotando o princípio de Pareto, temos uma ordenação na qual $p$ é preferível a $l .{ }^{21}$

Pensando, no entanto, de acordo com valores liberais, o ideal seria que o indivíduo libidinoso lesse o livro ao invés de ninguém ler, já que o que ele lê é da conta dele, (l é preferível a o). Ainda seguindo esses valores, é preferível que ninguém leia o livro a que o moralista o leia, já que ler ou não o livro deveria ser só da conta dele, e ele não deseja de fato ler o romance (o é melhor que $p$ ). Assim chega-se a um ciclo intransitivo, no qual $p$ é pre-

20 Para demonstrar este ponto de vista, Sen utiliza uma estrutura analítica muito próxima da exposta por Arrow, mas menos restrita em alguns pontos - não exige, por exemplo, a transitividade da escolha social (imposta pela Condição 2 de Arrow). Ele parte de uma função de decisão social e estabelece três condições que essa função deve respeitar para garantir a compatibilidade entre a regra de Pareto e o direito a uma esfera mínima de liberdade de decisão individual: 1) Condição U (domínio irrestrito). Todo conjunto logicamente possível de ordenamentos individuais está incluso no domínio da regra de escolha social (Sen, 1970, p. 153); 2) Condição P (Princípio de Pareto). Se cada indivíduo prefere qualquer alternativa $x$ a outra alternativa $y$, então a sociedade deve preferir $x$ a $y$ (Sen, 1970, p. 153); 3) Condição $L^{*}$ (liberalismo mínimo). Há ao menos dois indivíduos tais que para cada um deles existe ao menos um par de alternativas sobre as quais ele é decisivo, ou seja, há um par de $x, y$ tal que se ele prefere $x$ a $y$, a sociedade prefere $x$ a $y$ (Sen, 1970,p. 153). O resultado ao qual ele chega é o da impossibilidade de um Liberal Paretiano: Teorema 1: Não há uma função de decisão social capaz de satisfazer simultaneamente as Condições U, P e L (Sen, 1970, p. 154).

21 No texto, esses valores liberais estão associados à ideia, comumente aceita, de que cada um deve ter a liberdade de decidir sobre algumas esferas da sua vida, independentemente da opinião do restante da sociedade. Esse princípio está formalizado no texto nas condições "Condição L" (de liberalismo) e L* (de liberalismo mínimo) (Sen, 1970, p. 153-154). 
ferível a $l, l$ é preferível a $o$, e o é preferível a $p$, que implica no resultado da impossibilidade do liberal paretiano.

Dito de outra forma, se a regra de Pareto é adotada, não há garantia de que existam espaços nos quais a decisão possa ser apenas individual - que $\mathrm{o}$ "[...] indivíduo seja livre para ler o que deseja, dormir da forma que preferir, se vestir como queira, etc., independentemente das preferências de outros da comunidade." (Sen, 1970, p. 157, grifo no original). ${ }^{22}$

Assim, diante da impossibilidade de garantir o respeito simultâneo a todas as condições impostas, Sen se recusa a abrir mão da liberdade individual e conclui que "[...] se uma pessoa partilha de alguns ideais liberais, então ela tem que abdicar à sua adesão à otimalidade de Pareto" (Sen, 1970, p. 157).

Uma vez que Arrow na sua Condição 1 estabelece a obediência à regra de Pareto, podemos entender as críticas que Sen direciona a esse princípio como uma crítica bastante contundente à estrutura de Arrow. ${ }^{23}$

\subsection{Críticas associadas à Condição 2}

Esta condição estabelece um ponto importante sobre a estrutura do teorema de Arrow, que diz respeito à exigência de completude para a racionalidade da escolha social.

Como vimos, de acordo com a Condição 2, a transitividade e a completude são quesitos necessários para garantir que o resultado do procedimento de escolha social seja um ordenamento logicamente possível. Sen discor-

22 Sen diz que esse resultado aparece apenas em algumas configurações de preferência e que "[...] a garantia última da liberdade individual pode descansar não nas regras para a escolha social, mas no desenvolvimento de valores individuais que respeitem as escolhas de outras pessoas. $O$ conflito aqui colocado se refere a sociedades onde tal condição não prevalece, e nas quais as escolhas aos pares baseadas em valores liberais podem entrar em conflito com aquelas baseadas no Princípio de Pareto." (Sen, 1970, p. 155-6).

23 É muito importante enfatizar, entretanto, que a rejeição do princípio de Pareto, do modo em que geralmente é utilizado, não significa ignorar os desejos dos membros da comunidade. Nesse caso, é relevante notar a diferença entre "'preferir $x$ a $y$ ' e querer que as preferências dos membros 'contém a favor de $x$ contra $y$ '" (Sen, 1982, p. 315). Como veremos adiante, a crença no princípio da liberdade individual (que é uma informação não necessariamente associada à utilidade), permite que mesmo que alguém prefira que o outro não leia o livro, entende que esse outro tem o direito de lê-lo se quiser. No entanto, apesar de Sen não concordar com a escolha automática que a regra de Pareto condiciona, ele julga necessário considerar as preferências dos membros nas escolhas sociais. Alguns exemplos ilustrativos deste conflito entre a liberdade e a regra de Pareto podem ser encontrados em Sen (1982, p. 387-389). 
da e considera irracional que a escolha social deva ter a completude como pressuposto de racionalidade (Sen; Williams, 1982; Sen, 1982). Com relação a essa crítica, a figura do asno de Buridan é recorrente nos escritos de Sen:

A verdadeira "irracionalidade" do asno de Buridan repousa não em sua inabilidade em ranquear dois montes de feno, mas em sua recusa em escolher algum monte de feno sem estar perfeitamente certo de que o monte de feno era melhor que, ou ao menos tão bom quanto, o outro. (Sen; Williams, 1982, p. 17). ${ }^{24}$

Isso significa que, no que diz respeito à escolha social, em determinados casos é mais irracional não escolher nada - o que no caso do asno o fez morrer de fome - do que aceitar uma de duas alternativas mesmo sabendo que ela pode não ser a melhor.

A racionalidade exige completude? É difícil ver por que deveria. Não ser capaz de ranquear pode ser frustrante, mas por si mesma dificilmente poderia ser vista como um fracasso da racionalidade [...] Pode ser argumentado que a escolha racional baseada em ordenações incompletas requer somente que uma alternativa inferior não seja escolhida. Isso teria exigido que o asno de Buridan escolhesse qualquer um dos montes de feno, mas não nenhum deles, que era claramente uma alternativa inferior. (Sen; Williams, 1982, p. 17).

Essa crítica explora, então, o conflito que emerge quando uma necessidade prática - representada pela fome do asno - esbarra numa exigência teórica de um ranqueamento completo entre os dois montes de feno. E, neste caso, como evidencia a passagem acima, Sen advoga a favor da prioridade da primeira sobre a segunda. A própria noção clássica de racionalidade da teoria do bem-estar social é invertida e passa a ser vista a partir da dimensão prática da teoria da escolha social. Assim, para Sen, "[...] a exigência de completude não é nem metodologicamente razoável nem substancialmente plausível [...]" (Sen, 1985, p. 200).

\subsection{Críticas associadas à base informacional (Condição 3)}

No centro das críticas de Sen à teoria da escolha social de Arrow está, como mencionado, a questão da base informacional estreita. Boa parte

24 Sobre a fábula do asno de Buridan, Sen afirma: "A interpretação tradicional da história é que o asno era indiferente entre os dois montes de feno. [...] Mas de fato não há nenhuma causa real para hesitar caso seja realmente indiferente, já que a perda por escolher uma alternativa ao invés da outra é exatamente zero [...] Esse, entretanto, não é o caso se a preferência não for conectada no que concerne a esse par, i.e., se aquele que escolhe não consegue dizer que ele prefere $x$ a $y$, nem $y$ a $x$ e nem que é indiferente entre os dois." (Sen, 1982, p. 61 - 62). 
da limitação do universo de informações consideradas na escolha social é introduzida pela Condição 3 (independência das alternativas irrelevantes), que é descrita por Sen da seguinte maneira:

A ordenação social [social ranking] de qualquer par de estados tem que ser a mesma enquanto as informações de utilidade individual a respeito deste par permanecerem iguais; o que, no caso especial de utilidades ordinais e não-comparáveis, implica que as ordenações individuais sobre o par permanecerão inalteradas. (Sen, 1982, p. 330). 25

Dado que as ordenações individuais refletem, em última instância, as utilidades que os indivíduos associam às diferentes alternativas, pode-se dizer que essa condição exige que a utilidade seja a única informação relevante para a escolha social. ${ }^{26}$ Nesse sentido, as críticas que Sen dirige ao welfarismo - que "[...] implica que quaisquer dois estados de coisas que são idênticos em termos de características de utilidade individuais devem ser julgados igualmente bons não importando quão diferentes são em termos de características não referentes à utilidade [...]" (Sen, 1979, p. 464) - se aplicam à teoria da escolha social de Arrow. ${ }^{27}$

Para Sen (1982), valores que não se referem necessariamente à utilidade individual como o apreço pela liberdade e pelo respeito aos direitos huma-

25 Em outra interpretação da mesma condição, Sen diz "[...] A condição de independência exige que, no contexto da escolha a partir do conjunto $S$, todas as informações que não as ordenações individuais dos elementos de $S$ por cada pessoa devem ser consideradas irrelevantes e tais informações não podem influenciar a escolha social sobre S [...] (Sen, 1985, p. 171 , grifo no original). Nesse caso ele somente se refere à ordenação sem qualquer menção à utilidade, mas Sen parece acreditar que há uma íntima relação em Arrow entre utilidade e preferência. Tanto que ele descreve o empreendimento de Arrow da seguinte forma: "[...] [ele] definiu uma função de bem-estar social (FBS) como uma função que determina uma ordenação $\mathrm{R}$ dos conjuntos de estados sociais para cada combinação de ordenação de utilidade individual desse conjunto - uma ordenação para cada indivíduo." (Sen, 1982, p. 329). E enfatiza que a noção de utilidade que está subjacente a esse sistema é a de utilidade ordinal e não comparável: "Ao restringir a sua atenção às combinações de ordenações individuais tomadas em si mesmas, tanto o ordinalismo como não comparabilidade de utilidades [non comparable utilities] são incorporadas à própria ideia de uma FBS." (Sen, 1982, p. 329).

26 Apesar de tratarmos de welfarismo na seção que discute a Condição 3, isso não é totalmente preciso. Sen (1982, p. 329-330) deixa claro que apesar de o welfarismo implicar a independência de alternativas irrelevantes, o inverso não é verdadeiro. É a conjunção da Condição 3 com as outras 2 Condições (paretianismo fraco e racionalidade da escolha social) que implica welfarismo na estrutura de Arrow.

27 É interessante notar que essa crítica está associada à crítica que Sen faz ao critério de Pareto (ou seja a crítica à condição 1), pois esta também implica em uma crítica ao welfarismo. Uma vez que estabelece que o único critério de avaliação seria a utilidade, o welfarismo se associa de forma próxima ao Paretianismo - no caso de Arrow, ao paretianismo fraco - "[...] que exige que se um estado tem mais utilidade para todas as pessoas do que outro, então ele é um estado melhor." (Sen, 1979, p. 464). Para Sen, o paretianismo fraco é "[...] uma forma amena de welfarismo." (Sen, 1979, p. 464). 
nos; a rejeição à discriminação, à exploração, à pobreza, às desigualdades importantes de renda, de gênero, entre outros, são informações que devem ser consideradas na decisão social - e isso apresenta um desafio para teorias de natureza utilitarista (como a de Arrow).

[...] alguns princípios morais são formulados sem fazer qualquer uso de informações referentes à utilidade, por exemplo, "igual pagamento para igual trabalho", "não exploração", etc., e é fácil demostrar que esses principios iriam conflitar com o welfarismo, que torna decisiva a informação referente à utilidade. (Sen, 1982, p. 340). ${ }^{28}$

Ao assumir como única fonte de informação as preferências individuais pelos estados sociais (Condição 3), a estrutura arroviana não possibilita, a priori, garantir, por exemplo, que todos devem ter direito, à liberdade, ao acesso à justiça ou a um mínimo de alimentação diária. De fato, nada impede que esse seja o resultado da escolha social, mas também nada garante que seja. Uma das poucas coisas que se pode dizer de início quando observamos as condições de Arrow é que, como já foi dito, o processo de escolha social não será ditatorial.

Assim, a Condição 3 impede a inclusão de temas considerados essenciais por Sen na discussão sobre escolha social, já que ela não admite nenhum tipo de viés, ou seja, a escolha entre dois estados sociais $x$ e $y$ deve ser pautada apenas nas preferências individuais sobre esses estados. Outras características como a presença de direitos básicos amplamente compartilhados, a distribuição mínima de bens e serviços considerados essenciais ou a presença de instituições, como o sistema judiciário, não devem ser levadas em consideração na escolha social..$^{29}$

28 Isso aparece claramente na questão da liberdade discutida anteriormente: "Atenção à liberdade [considerations of liberty] requer especificar informações não referentes à utilidade como relevantes, eg. se a escolha considerada é autorreferente ou não (cf. Mill, 1859), ou cai na 'esfera protegida' da pessoa (cf. Hayek, 1960)." (Sen, 1982, p. 342).

29 Para Sen (1982, p. 335), a estrutura do teorema de Arrow não permite nem mesmo identificar em um grupo de indivíduos quem são os ricos e os pobres. Não é possível identificar os ricos com base na afirmação de que possuem mais utilidade (pois não se permite comparações interpessoais); não é possível afirmar que os ricos são aqueles que têm menor utilidade marginal da renda (que requereria não só comparações interpessoais como também uma medida cardinal de utilidade, ambas excluídas da análise); e não é possível identificar os ricos como aqueles que têm mais renda ou acesso maior a bens de consumo (uma vez que isso envolve informações não referentes à utilidade, também descartada). Isso certamente constitui um problema para alguém, como Sen, que está preocupado com questões de distribuição de renda e desigualdades sociais - e que quer formular políticas para minorar a pobreza ou garantir, pelo menos, um mínimo de recursos para todos os cidadãos. 


\subsubsection{A necessidade de ampliação da base informacional}

Essas reflexões sobre a pobreza da base informacional utilizada pela teoria da escolha social de Arrow foram fundamentais para os trabalhos subsequentes de Sen. Para ele, "[e]sse cenário infértil [barren landscape] torna difícil chegar a julgamentos sistemáticos de bem-estar social" (Sen, 2002, p. 271) e isso levou-o a expandir (drasticamente) essa base informacional de modo a incorporar na sua análise tanto informações não-referentes à utilidade e como comparações interpessoais (de utilidade e de outros elementos).

$\mathrm{Na}$ avaliação de Sen, diferentemente "[d]o que a interpretação popular frequentemente julga" a conclusão de Arrow "[...] não prova a impossibilidade da escolha social racional, e sim a impossibilidade que emerge quando tentamos basear a escolha social em uma classe limitada de informações" (Sen, 1999, p. 287-288). Sob este ponto de vista, o que o teorema da impossibilidade de Arrow na verdade explicita é a inconsistência entre uma base informacional que considera somente os rankings de preferências individuais e regras de decisão social minimamente democráticas. Assim, Arrow teria demonstrado de maneira cabal a necessidade de ampliar a base informacional da economia do bem-estar.

No entanto, a ampliação na base informacional defendida por Sen foi muito além daquela que seria necessária meramente para "contornar" o problema da Impossibilidade. ${ }^{30} \mathrm{O}$ resultado da impossibilidade de Arrow deixou explícitas as limitações desse tipo de abordagem para tratar as questões que estavam no centro das preocupações de Sen, como a pobreza, a desigualdade, a discriminação - o que a tornava imprópria para os seus fins. Isso ofereceu ao autor uma oportunidade para a construção de sistemas de escolha mais compromissados com a justiça social e a liberdade. E, como resultado, Sen desenvolveu o que ficou conhecido como a "abordagem das capacitações". ${ }^{31}$

30 Segundo o autor: "regras de avaliação social baseadas em informações de utilidade mais ricas [cardinalidade e comparações interpessoais] escapam de problemas de Impossibilidade do tipo de Arrow, mas na medida em que a estrutura [framework] welfarista, (ou estritamente welfarista) é mantida, outras dificuldades aparecem. Existem princípios de avaliações sociais que requerem o uso de informações não referentes à utilidade, e ainda que tais princípios (ex.: liberdade, não-exploração, não-discriminação) não sejam tipicamente muito discutidos na economia do bem-estar tradicional, eles estão bastante relacionados ao assunto." (Sen, 1982, p. 338).

31 Sen desenvolve a sua abordagem das capacitações em inúmeros textos, por exemplo, Sen (1982; 1985; 1999). 
Nessa abordagem, a ideia de que se deve buscar a igualdade de "oportunidades reais" (ou substantivas) é central. Como destaca Mendes (Sen, 2001, p. 13), o termo "oportunidade real" deve ser entendido como o conjunto formado pelos meios para a realização de um determinado fim e pela existência de um contexto favorável à realização desse fim. Sendo assim, o que deve ser levado em conta na avaliação de um estado social é a sua capacidade de garantir aos seus membros as condições mínimas (meios) para que possam viver a vida que individualmente valorizam (fins), levando-se em conta que existem diferenças interpessoais importantes entre esses participantes. ${ }^{32}$ Desse modo, um estado social desejável deve ser sensível às diferenças interpessoais no potencial de conversão de recursos (bens, direitos, serviços, instituições, etc.) em resultados individualmente valorizados $^{33}$ e que, além disso, ampliem as "oportunidades reais" dos membros da comunidade.

Assim, Sen se afasta do welfarismo, que vimos estar subjacente às teorias de bem-estar social e da escolha social, e defende uma base informacional mais ampla como a medida mais correta para se avaliar e escolher os estados sociais. ${ }^{34}$ É importante notar que a sua análise envolve fartamente a utilização de comparações interpessoais (mesmo que sejam parciais). ${ }^{35}$ No entanto, a sua ênfase não recai na comparação interpessoal de estados

32 Segundo essa perspectiva, uma sociedade justa é aquela em que os seus membros possuem a liberdade para escolher viver o tipo de vida que valorizam. Nessa sociedade justa, tanto o contexto quanto os meios que uma pessoa possui devem ser capazes de permitir que ela consiga ter o tipo de vida que deseja ter. Se o indivíduo valorizar a profissão e desejar ser médico, ele deve ter os meios para, mediante seus esforços, conseguir sê-lo. Se ele valoriza uma vida sem compromissos, deve poder ser, por exemplo, um andarilho, responsabilizando-se por todas as consequências que essa escolha envolve. O caráter abstrato da noção de "oportunidades reais" não é encarada por Sen como um empecilho. Esse conceito é considerado pelo autor como um método, uma maneira de se avaliar quais tipos de instituições, serviços, bens e direitos são mais importantes e mais urgentes na busca pela igualdade nesse aspecto.

33 Em sua obra, Sen utiliza mais especificamente o termo "funcionamentos" (functionings) para expressar essa ideia. Em seus próprios termos, funcionamentos "referem-se a 'atividades' (como ver, comer) ou 'estados de existência ou ser' [states of existence or being] (como estar bem nutrido, estar livre da malária, não estar envergonhado pela pobreza da roupa vestida); por vezes abreviados por 'ações' [doings] e 'estados' [beings]" (Sen, 2001, p. 236). Assim, os estados sociais em que os indivíduos possam realizar funcionamentos por eles valorizados e funcionamentos que ampliem suas oportunidades reais, devem ser mais valorizados que outros que não possuem essa característica.

34 Para uma crítica ao welfarismo e sobre a necessidade de ampliar a base informacional ver, por exemplo, Sen (1982; 1979; 1985; 2011).

35 "A extensão da comparação interpessoal pode ser somente parcial [...] Mas os uso de tal comparabilidade parcial pode fazer uma diferença grande na base informacional de julgamentos sociais arrazoados [reasoned social judgements]." (Sen, 2002, p. 84). 
mentais (ou utilidade), ou de quantidades de bens primários ou recursos - apesar de ele não descartá-las para fins práticos. Para ele, torna-se fundamental levar em conta as diferenças interpessoais existentes na conversão dos bens e recursos em "[...] capacidade de viver bem" (Sen, 2002, p. 83). Ele entende que com essa ampliação informacional "[...] é possível chegar-se a critérios coerentes e consistentes para a avaliação social e econômica" (Sen, 2002, p. 288).

\section{Considerações finais}

Em uma entrevista a Arjo Klamer, Amartya Sen afirma que seu interesse por Economia foi natural por ter nascido na Índia onde "[...] os problemas econômicos nos engolem [engulf]" (Klamer, 1989, p. 136) e relata que ainda menino ficou muito impressionado com o episódio de fome que, pelos seus cálculos, causou a morte de aproximadamente 3 milhões de pessoas em Bengala em 1943. Assim, o seu direcionamento para essa disciplina teria sido um movimento natural. Ele afirma ainda que seu envolvimento com essa ciência "[...] teve um componente de paixão social em adição à fascinação intelectual." (Klamer, 1989, p. 136).

De fato, o trabalho desenvolvido por Sen envolve de forma importante essas duas dimensões: uma teórica (formal e matemática) e outra prática, voltada a dirimir os problemas sociais sérios que o circundavam. ${ }^{36} \mathrm{O}$ autor sempre fez questão de utilizar o conhecimento teórico para discutir problemas de países subdesenvolvidos (e de alguns países desenvolvidos) e para tentar descobrir formas para mitigar a pobreza, a ocorrência da fome, melhorar a condição das mulheres nos países em que há extrema desigualdade de gênero, ou dirimir outras situações responsáveis por fazer com que algum segmento da sociedade passe por privações importantes (avaliadas não somente em termos de renda). ${ }^{37} \mathrm{E}$ as teorias no campo do

36 Essa mistura, hoje em dia pouco usual, é defendida explicitamente por ele. Ele defende a formalização e matematização tanto como forma de chegar a resultados não antecipados e pouco intuitivos (como o próprio resultado "surpreendente" da Impossibilidade), como também forma de evitar erros e inconsistências. Todavia, o autor diz que sempre exigiu que esse raciocínio formal estivesse integrado com as suas "[...] profundamente sentidas, preocupações com o mundo real [deepley felt, real-world concerns]" (Sen, 2002, p. 73-74).

37 Ao enfatizar a importância destes aspectos, Sen contribuiu para que muitos economistas se voltassem à investigação destas questões. Como coloca Atkinson "no campo da disciplina da economia, ele tem sido excepcionalmente bem-sucedido em criar interesse da profissão 
bem-estar social e da escolha social na época em que começou a estudá-las não forneciam um instrumental adequado para esses fins.

A ânsia (metodológica) de expurgar considerações éticas do campo da ciência econômica teria levado a um paulatino estreitamento da base informacional que, além de tornar essas teorias inadequadas para tratar de forma profícua e significativa as questões do mundo-real que tanto preocupavam Sen, culminou no resultado da Impossibilidade de Arrow.

Esse resultado foi um marco importante nas reflexões de Sen sobre bem-estar e escolha social, pois teria deixado claro que o caminho sugerido pela Nova Teoria do Bem-Estar Social e seguido por Arrow (de ter um comprometimento ético mínimo representado pelo critério de Pareto, de lidar apenas com noções ordinais de utilidade e rejeitar comparações interpessoais da mesma) levava a um beco sem saída no campo da escolha social. Tornar a teoria adequada para lidar com as questões práticas que o mobilizavam exigia não só reintroduzir noções de cardinalidade e comparações interpessoais de utilidade, que foram abandonadas ao longo do tempo pelos economistas, mas também trazer para o campo das discussões sobre bem-estar e escolha social reflexões éticas sobre o valor da liberdade, da igualdade, do respeito aos direitos humanos, etc.

Vimos que, como resultado da reflexão sobre o que seria crucial para que uma teoria da escolha social fosse adequada para lidar com os problemas existentes na sociedade, Sen acaba por rejeitar 3 das 4 Condições que Arrow exigiu que a FBS respeitasse - e que geraram o resultado da impossibilidade. Rejeita o critério de Pareto (Condição 1), por conta de considerações sobre liberdade; rejeita os pressupostos de racionalidade que embasam a Condição 2, por considerar que a solução de problemas práticos, que podem vir de ordenamentos incompletos, deve prevalecer sobre a exigência de completude; e, por fim, rejeita o welfarismo, derivado da adoção conjunta dessas duas condições com a de independência das alternativas irrelevantes (Condição 3), - por resultar numa base informacional por demais pobre para embasar as decisões sociais.

pelos assuntos nos quais ele se concentra, afetando significativamente a evolução da disciplina. De fato, uma das suas principais contribuições tem sido legitimar a investigação de alguns tópicos - tais como fome [famine] - que antes eram vistos por muitos como estando fora das preocupações da profissão." (Atkinson, 1999, p. 189). A sua abordagem das capacitações ficou mais conhecida do grande público ao inspirar a visão de desenvolvimento adotada pelo PNUD e o seu principal indicador - o Índice de Desenvolvimento Humano (IDH). Esse indicador tenta captar a qualidade de vida observando dados não só de renda, mas também aspectos concernentes ao nível de conhecimento e saúde da população. 
Enfim, Sen enxergou no resultado da Impossibilidade uma oportunidade para a ampliação dos objetivos da teoria econômica do bem-estar. Essa mudança de perspectiva colocou novos e importantes desafios teóricos e práticos. O debate ético, travado no campo da filosofia do direito, sobre o qual deve ser o tipo de igualdade a ser defendida, e a discussão moral sobre o que deve ser considerada a boa vida, são exemplos dos novos desafios teóricos que ele resolveu encarar. Do ponto de vista prático, passaram a fazer parte dos desafios o estabelecimento de métricas para se avaliar o grau de desenvolvimento humano e a construção de índices capazes de mensurar o grau de liberdades substantivas desfrutados pelos cidadãos.

Em síntese, é possível dizer que para Sen o teorema da impossibilidade de Arrow demonstrou a necessidade de reintrodução da perspectiva ética e humanitária nas discussões da economia do bem-estar. Para ele, a economia do bem-estar deve ser um instrumento para o desenvolvimento humano.

\section{Referências}

ALLÉN, T. The Impossibility of a Paretian Liberal and its Relevance to Welfare Economics. Theory and Decision, 24. D. Reidel Publishing Company,1988.

ARROW, K. J. Social Choice and Individual Values. New Haven and London: Yale University Press, 1963.

ATKINSON, A. B. The Contributions of Amartya Sen to Welfare Economics. Scandinavian Journal of Economics, v. 101, issue 2, p. 173-90, 1999.

HANDS, W. Reflexion without rule: economic methodology and contemporary science theory. Cambridge University Press, 2001.

HAYECK, F. A. The Constitution of Liberty. London: Routledge, 1960.

KLAMER, A. A Conversation with Amartya Sen. The Journal of Economic Perspectives, v. 43, n. 1, p. 135-50, 1989.

MILL, J. S. On liberty. Reimpresso em: MILL, J. S. Utilitarianism: On Liberty; Representative Government. Everyman's Library, 1859.

ROBBINS, L. An Essay on the Nature and Significance of Economic Science. London: Macmillan, 1932. SAMUELSON, P. A. Fundations of Economic Analysis. Cambridge: Harvard University Press, 1963. SEN, A. K. The Impossibility of a Paretian Liberal. Journal of Political Economy, v. 78, n. 1, p. $152-$ 157, 1970. Disponível em: http://www.jstore.org/stable/1829633. Acesso em 24/09/2012. SEN, A. K. Utilitarism and Welfarism. The Journal of Philosophy, v. 76, n 9, p. 463-89, 1979.

SEN, A. K. Choice, Welfare and Measurement. Oxford: Basil Blackwell, 1982.

SEN, A. K. Well-being, agency and freedom: the Dewey Lectures 1984. Journal of Philosophy, 
v. 82, 1985.

SEN, A. K. Desenvolvimento como liberdade. São Paulo: Companhia das Letras, 1999.

SEN, A. K. Desigualdade reexaminada. Rio de Janeiro: Record, 2001.

SEN, A. K. Rationality and Freedom. Cambridge, MA: Harvard University Press, 2002.

SEN, A. K. The informational basis of social choice. In: ARROW, K. J.; SEN, A. K.; SUZUMURA, K. (Orgs.) Handbook of social choice and welfare, v. 2, UK: Oxford, 2011, p. 29-46.

SEN, A. K; WILLIAMS, B. (Orgs.). Utilitarianism and Beyond, Cambridge: Cambridge University Press, 1982.

STRASNICK, S. The problem of Social Choice: Arrow to Rawls. Philosophy and Public Affairs, v. 5 , n. 3, p. 241-273, 1976.

SUZUMURA, K. Introdução . In: ARROW, K. J.; SEN, A. K.; SUZUMURA, K. (Orgs.) Handbook of Social Choice and Welfare. v. 1. UK: Oxford, 2002. p. 1-32.

SUZUMURA, K. An interview with Paul Samuelson: Welfare Economics, "Old" and "New" Social Choice Theory, 2004. In: http://hermes-ir.lib.hit-u.ac.jp/rs/bitstream/10086/16143/1/ 070resDP_37.pdf. Acesso em 23/07/2014.

\section{Sobre o autor}

Bruno Beltrame - bruno.beltrame@gmail.com

Pontifícia Universidade Católica de São Paulo - PUCSP, São Paulo, SP.

Laura Valladão de Mattos - Lauramattos@usp.br

Faculdade de Economia, Administração e Contabilidade da Universidade de São Paulo - USP, São Paulo, SP.

\section{Sobre 0 artigo}

Recebido em 27 de fevereiro de 2015. Aprovado em 18 de janeiro de 2016. 